\title{
Plano Ceibal e a educação virtual formal no Uruguai
}

\section{Ceibal plan and formal virtual education in Uruguay}

Jorge Delgado Lasa, professor da Administración Nacional de Educación Publica (ANEP) do Uruguai, mestre em Educação com especialização em Tecnologias Educativas, é o atual diretor do Departamento de Tecnologia Educativa e Ceibal (Conectividade Educativa e Informática Básica para a Aprendizagem on-line) do Conselho de Educação Inicial e Primária da ANEP do Uruguai.

Contato: ceibal2014@gmail.com

\section{Resumo}

As primeiras expressões da educação virtual para professores do ensino infantil e primário no Uruguai, na esfera formal, datam de 2001. Alguns anos depois, com a implementação do Plano Ceibal (Conectividade Educativa e Informática Básica para a Aprendizagem on-line) e a criação do Departamento de Tecnologia Educacional e Ceibal, iniciase um processo no qual se diversificam as propostas de formação nessa modalidade e sua abrangência entre os docentes é ampliada. Esse processo foi favorecido porque o plano previu a entrega de um laptop gratuito para todos os professores do Conselho de Educação Infantil e Primária, além de garantir acesso à internet nas instituições onde eles exercem suas funções.

Palavras-chave: Educação virtual. Formação docente. Política educacional.

\section{Abstract}

The first formal expressions of virtual education for kindergarten and primary school teachers in Uruguay date back to 2001. A few years later, with the implementation of the Ceibal Plan and the creation of the Department of Educational and Ceibal Technology, begins a process in which the training proposals in this modality are diversified, and 
its scope among the teachers is expanded. This process was successful because the plan provided a laptop, for free, to all teachers of the Council of Early Childhood Education, as well as ensuring access to the internet in the institutions where they perform their duties.

Keywords: Virtual education. Teacher education. Educational policy.

\section{Origens e avanços da educação virtual no âmbito do CEIP}

A origem da modalidade de Educação Virtual (EDV) no âmbito do Conselho de Educação Infantil e Primário (CEIP) da Administração Nacional de Educação Pública (ANEP) do Uruguai resulta da constante transformação da educação em nível geral, originada pelas oportunidades e demandas das mudanças permanentes vividas na sociedade atual.

Nesse sentido, o século 20 inaugurou um novo cenário de possibilidades ao público, já que a vida pessoal e social foi rapidamente transformada pelas dinâmicas tecnológicas. Essa realidade determina que a modalidade de formação presencial seja questionada, tanto pelo funcionamento das próprias instituições quanto pelos profissionais envolvido nelas.

No que se refere à atuação do CEIP, a origem da educação virtual data de abril de 2001, quando a ANEP implementou o Programa de Conectividade Educacional, que, entre suas linhas de ação, incluiu cursos on-line no portal Todos en Red, destinado aos docentes. Embora o escopo desse projeto tenha sido limitado, foi também um dos primeiros casos de formação semipresencial, com a participação de 1.228 professores. 0 curso abrangeu conteúdos como: uso da plataforma de e-learning, conhecimentos básicos de tecnologias da informação e da internet, introdução à Educação a Distância, navegação e buscas na web, uso de email e Office 2003 (GROMPONE et al., 2007).

\section{Educação virtual no Plano Ceibal}

Em abril de 2007, com a implementação do Plano Ceibal ${ }^{1}$, essas possibilidades foram ampliadas massivamente, basicamente por duas razões: cada professor e cada aluno de escola pública do país recebeu um laptop pessoal, e, nos anos seguintes, todas essas escolas receberam internet gratuita. Em 2013, a Plataforma
1. CEIBAL: Conectividade Educativa e Informática Básica para a Aprendizagem on-line. Essa palavra também possui outro significado para os uruguaios, já que ceibal é o conjunto de árvores chamadas Ceibos. A flor dessa árvore é a flor nacional do Uruguai. 
Educacional CREA $^{2}$ passou a ser utilizada como uma experiênciapiloto que, a partir de sua melhoria em 2014, foi oferecida a todas as escolas públicas do país ${ }^{3}$.

Ao mesmo tempo, foram criados novos atores de ensino: Professores Impulsionadores, Professores de Apoio Ceibal, Tutores Virtuais e Professores Conteudistas, que, em 2010, foram integrados ao Organograma do Departamento de Educação e Tecnologia Ceibal do CEIP (DTEC) - criado por meio da Lei $\mathrm{n}^{0} 59$, Res. $N^{\circ} 2$, do CEIP, de 22 de novembro de 2010 (Anexo I).

O DTEC tem como objetivo assessorar os grupos de ensino e promover, em todos os níveis, a possibilidade de expansão do uso da plataforma virtual CREA, como uma oportunidade de ampliar o acesso dos professores à formação, por meio da modalidade de aprendizado misto (b-learning ou semipresencial) ou eletrônica (e-learning, ou educação a distância ou virtual).

Em relação à formação, as diferentes unidades de inspeção técnica do CEIP (Anexo II) também visualizaram os dispositivos tecnológicos e serviços de conexão que os professores possuem como uma oportunidade de acesso. 0 mesmo se aplica a outras unidades do CEIP que tinham, naquela época, a formação continuada de professores como principal tarefa.

O Projeto de Apoio à Escola Pública do Uruguai (PAEPU) ${ }^{4}$, criado no final dos anos 1990, que tem como parte de suas atividades a formação presencial, sistemática e permanente de professores da pré-escola e Ensino Fundamental, bem como diretores e inspetores de todas as escolas de período integral, também se aventura no planejamento de cursos em turmas mistas.

Situação semelhante ocorre no Instituto de Formação em Serviço, criado pela Circular $n^{\circ} 3$, Lei $n^{0} 7$, de 6 de fevereiro de 2014 , do CEIP, que inclui a modalidade mista nas propostas de formação de docentes e as oferece aos professores em serviço ${ }^{5}$.

Também nesse contexto, no âmbito das Inspeções Departamentais são geradas instâncias de treinamento virtual promovidas pelos Diretores-Gerais dos Inspetores Referenciais do CTEC e Ceibal, por meio das quais os diferentes grupos de ensino são aconselhados.
2. CREA: é uma sigla que significa: Criar Recursos para a Aprendizagem e Ensino. É uma versão da Plataforma Schoology

3. Ceibal en números (dados de 22 de junho de 2019). Disponível em: https://www.ceibal.edu. uy/es/articulo/ceibal-en-cifras

4. Fonte: PAEPU: https://www. mecaep.edu.uy/innovaportal/v/29/1/paepu/institucional. html

5. Fonte IFS: http://www.ceip. edu.uy/IFS/index . php? option=com_content\&view =feature d\&ltemid $=101$ 


\section{EDV desenvolvido pelo DTEC}

Para o DTEC, a formação continuada de professores associada à integração educacional das tecnologias, por meio da modalidade semipresencial ou virtual, é uma das principais linhas de intervenção. A partir disso, nos últimos anos, decidiu-se diversificar a formação de acordo com as necessidades de cada professor com um acompanhamento duplo: virtual, fornecido pelo próprio DTEC, por meio dos Professores Tutores, e presencial, in loco, responsável pelos Professores Impulsionadores, Professores de Apoio Ceibal ou Diretores do CTEC (Anexo III).

Um exemplo é o Plano de Formação para o Professor de Referência Tecnológica (For.Ma.R.Te.). Proposto pela gerência do DTEC em dezembro de 2014 para a Inspeção Técnica e aprovado pelo CEIP por meio da Lei $\mathrm{n}^{\circ} 74$, Res 3, de 28 de dezembro de 2015 , ele é uma das principais linhas de formação semipresencial que o DTEC desenvolve durante o atual período de cinco anos. Sua principal tarefa é fortalecer os novos professores, por meio de apoio sistemático in loco, com a assistência dos Professores Impulsionadores e apoio virtual, a cargo dos Tutores Virtuais, com o objetivo fundamental de pensar em estratégias para fortalecer os projetos pessoais gerados pelos participantes. 0 desafio é que a formação seja adaptada ao projeto do professor participante, e não vice-versa.

0 plano é fundamentado em pesquisas conduzidas pela gerência do DTEC durante os anos de 2014 a 2015 (DELGADO, 2015), cujas conclusões mostram que os novos professores se encontravam em uma situação vulnerável que, até então, era pouco contemplada.

A avaliação do For.Ma.R.Te. indica que os desafios levantados no início foram superados: no final do processo desenvolvido durante um ano letivo, cada participante apresentava conhecimento e habilidades digitais para continuar aprofundando a integração educacional das tecnologias em sua prática profissional diária. Por outro lado, os participantes passam a trabalhar como referenciais tecnológicos que dinamizam a instituição para que o grupo de ensino possa otimizar a integração das TICs no projeto institucional. Da mesma forma, é possível aproveitar os interstícios da dinâmica institucional para consultar, esclarecer dúvidas, superar obstáculos ou ampliar o conhecimento sobre aplicativos digitais ou softwares educacionais usados com frequência.

Outro exemplo é o Congresso Século 21: Educação e Ceibal, que 
consiste em outro dispositivo pedagógico promovido pelo DTEC, voltado para o desenvolvimento profissional docente. Baseia-se na reflexão sobre práticas profissionais, na análise de intervenções do ensino e seu confronto com contribuições teóricas de especialistas, que permitem produzir conhecimento para redirecionar e fortalecer o caminho pedagógico.

A origem remonta a 2010, quando o Departamento Soriano [equivalente a um estado no Brasil] proliferou a ideia de ter um espaço para esse fim (DELGADO, 2017, p. 12). Assim, em outubro daquele ano, surge a primeira edição do Congresso Século 21: Educação e Ceibal, no modo presencial e virtual. 0 processo continuou ininterruptamente, com novas edições planejadas pelo DTEC nas duas modalidades, ano após ano e em diferentes cidades do país.

A aderência e a participação em cada edição permitiram valorizar o apoio de todos os que favoreceram essa jornada. Destaca-se a relevância das contribuições de vários palestrantes que contribuíram para o fortalecimento de uma integração pedagógica de qualidade das tecnologias na educação. Alguns deles, como uma projeção das instâncias presenciais em que participaram na oportunidade de comemorar os dez anos do Plano Ceibal, retomaram e compartilharam ideias em um material publicado em outubro de 2017 e disponível no site do CEIP6 .

Da mesma forma, a criação, adaptação e publicação de recursos educacionais abertos nos portais educacionais Uruguay Educa e Ceibal, a cargo dos Professores Conteudistas do DTEC, foram integradas à formação virtual.

\section{A título de síntese}

Certamente, podemos concordar que o desenvolvimento profissional permanente do professor é uma das condições necessárias para a melhoria contínua dos processos educacionais e que, por outro lado, a formação continuada é um direito de todo profissional. Essas são duas condições básicas que nos levam a aderir e promover a partir do CEIP e, em particular, do DTEC, a modalidade de formação virtual como uma alternativa para expandir a cobertura e alcançar mais professores que esperam oportunidades de formação, nas quais o espaço e o tempo, diferentemente do contato pessoal, deixam de ser um obstáculo.
6. Livro Siglo XXI: Educación y Ceibal, disponível em: https:// sxxieducacionyceib. wixsite. $\mathrm{com} / \mathrm{misitio.}$ 


\section{REFERÊNCIAS}

Delgado, J. (2015). Necesidades de los noveles maestros uruguayos para la integración de las tecnologías de la información y la comunicación. Disponível em: https://docs.wixstatic.com/ugd/ a2c3ca_2dbcdb79ca8340c2ab994f2e7c1d3f2e.pdf. Acesso em: em 21 de jun. 19.

Delgado, J. (Coord.). (2017). Siglo XXI: Educación y Ceibal. ANEP-CEIP. Disponível em: https://sxxieducacionyceib. wixsite.com/misitio. Acesso em: 20 de jun. 2019.

Grompone, J. (2007) Evaluación del Programa de Conectividad Educativa. Disponível em: http://www. grompone.org/ineditos/educacion/InformePCE.pdf. Acesso em: 20 de jun. 2019.

Recebido: 20/08/2018

Revisto: 23/09/2019

Aceito: 23/09/2019 


\section{Anexo I}

Organograma do Departamento de Tecnologia Educativa e Ceibal do CEIP

Fonte:https://docs.wixstatic.com/

ugd/4f0a43_2952acd00365469bac9bae44310228a6.pdf

\section{Organograma do DTEC}

\section{Bloco 1: linhas 1 a 4}

\section{CEIP}

Inspeção Técnica

Inspetor Referência Ceibal pela Insp. Técnica

Diretor

\section{Bloco 2:}

Coord. Nacional de Formação e Conteúdos Digitais

Professores Conteudistas

Professores Tutores

\section{Bloco 3:}

Coord. Nacional de Centros de Tecnologia Educativa e Ceibal

Diretoria do Centro de Tecnologia Educativa e Ceibal

Professores Impulsionadores

Professores de Apoio Ceibal

\section{Bloco 4:}

Inspetor Referência Ceibal

\section{Bloco 5:}

Coord. Nacional da Rede Global de Aprendizagem

Professores Associados

\section{Bloco 6:}

Professores Capacitadores GURI

Professores associados a Mesa de Apoio GURI

Funcionários Administrativos

Motorista 


\section{Anexo II}

Organograma da Divisão de Inspeção Técnica do CEIP Fonte: http://www.ceip.edu.uy/documentos/2014/tecnica/ OrganizaSistemica.gif

\section{Bloco 1:}

Planejamento Educativo

Núcleo de Assistência Técnica

Departamentos

Bibliotecas e museus

Publicações e impressões

Educação para o meio rural

Tecnologia Educativa

Educação Privada

Capacitação de Professores em Serviço

\section{Bloco 2: Decisões centralizadas}

Inspeção Técnica

Inspeções Nacionais

Educação Básica

Educação Infantil

Escolas de Tempo Integral e C.S.C.C

Escolas Técnicas

Educação Especial

Educação Musical

Inspeções Departamentais

Escolas

Aulas

Bloco 3: Núcleo de controle

Avaliação

Controle Administrativo

Equipe e Inspetores 


\section{Anexo III}

\section{Cursos desenvolvidos pelo DTEC do CEIP nos últimos anos}

Fonte: https://ceibal2014.wixsite.com/departamento-ceibal/ formacion

\begin{tabular}{|c|c|c|c|c|c|}
\hline Proposta & Modalidade & Denominação & $\begin{array}{l}\text { Data de } \\
\text { execução }\end{array}$ & Destinatários & $\begin{array}{c}\text { № de } \\
\text { professores } \\
\text { formados }\end{array}$ \\
\hline Plano & B-learning & $\begin{array}{l}\text { For.Ma.R.Te. } \\
\text { Formação para } \\
\text { o Professor } \\
\text { de Referência } \\
\text { Tecnológica }\end{array}$ & $\begin{array}{l}2016 \text { a } 2019 \\
\text { (quatro } \\
\text { coortes) }\end{array}$ & $\begin{array}{l}\text { Novos } \\
\text { professores }\end{array}$ & 355 \\
\hline Curso básico & E-Learning & $\begin{array}{l}\text { Curso básico } \\
\text { Tecnologia em Sala } \\
\text { de Aula }\end{array}$ & $\begin{array}{l}2017 \text { a } 2019 \\
\text { (três coortes) }\end{array}$ & $\begin{array}{l}\text { Professores } \\
\text { do CEIP }\end{array}$ & 360 \\
\hline Curso & B-learning & $\begin{array}{l}\text { Curso de } \\
\text { Supervisão para } \\
\text { Professores } \\
\text { Diretores }\end{array}$ & $2015-2016$ & $\begin{array}{l}\text { Professores } \\
\text { Diretores } \\
\text { do CEIP }\end{array}$ & 206 \\
\hline Curso & B-learning & $\begin{array}{l}\text { Supervisão } \\
\text { Educativa com } \\
\text { Integração de TIC } \\
\text { Aportes para a } \\
\text { nova função de } \\
\text { supervisor }\end{array}$ & $\begin{array}{l}\text { 2016-2016 } \\
\text { (dois coortes) }\end{array}$ & $\begin{array}{l}\text { Professores } \\
\text { inspetores } \\
\text { do CEIP }\end{array}$ & 134 \\
\hline Curso & E-Learning & $\begin{array}{l}\text { Curso de tutoria } \\
\text { virtual }\end{array}$ & $\begin{array}{l}2015 \text { - } 2019 \\
\text { (dois coortes) }\end{array}$ & $\begin{array}{l}\text { Professores } \\
\text { do CEIP com } \\
\text { formação na área } \\
\text { da tecnologia }\end{array}$ & 133 \\
\hline Curso & B-learning & $\begin{array}{l}\text { Curso Pensamento } \\
\text { computacional e } \\
\text { Educação }\end{array}$ & $\begin{array}{l}2017-2019 \\
\text { (três coortes) }\end{array}$ & $\begin{array}{l}\text { Professores } \\
\text { integrantes das } \\
\text { equipes dos } \\
\text { Centros TEC } \\
\text { e Professores } \\
\text { Impulsionadores }\end{array}$ & 153 \\
\hline Curso & B-learning & $\begin{array}{l}\text { Curso Função e } \\
\text { Perfil do Professor } \\
\text { de Apoio Ceibal }\end{array}$ & $\begin{array}{l}2018-2019 \\
\text { (dois coortes) }\end{array}$ & $\begin{array}{l}\text { Professores de } \\
\text { Apoio Ceibal } \\
\text { e Professores } \\
\text { Impulsionadores }\end{array}$ & 312 \\
\hline Curso & B-learning & $\begin{array}{l}\text { Impulsionamento } \\
\text { de espaços virtuais }\end{array}$ & 2017 & $\begin{array}{l}\text { Formadores } \\
\text { do Instituto de } \\
\text { Formação } \\
\text { em serviço }\end{array}$ & 40 \\
\hline Curso & B-learning & $\begin{array}{l}\text { Curso de } \\
\text { Introdução } \\
\text { de Produção } \\
\text { de Conteúdos } \\
\text { Educacionais } \\
\text { Digitais }\end{array}$ & 2016-2017 & $\begin{array}{l}\text { Professores } \\
\text { em sala de aula }\end{array}$ & 140 \\
\hline Curso & E-Learning & $\begin{array}{l}\text { Curso A Proteção } \\
\text { de dados Pessoais }\end{array}$ & 2017 & $\begin{array}{l}\text { Professores } \\
\text { em sala de aula }\end{array}$ & 120 \\
\hline Curso & E-Learning & $\begin{array}{l}\text { Alimentação } \\
\text { e hidratação } \\
\text { saudável }\end{array}$ & 2016-2017 & $\begin{array}{l}\text { Professores } \\
\text { em sala de aula }\end{array}$ & 200 \\
\hline $\begin{array}{l}\text { Total de } \\
\text { professores } \\
\text { formados } \\
\text { no último } \\
\text { quinquênio }\end{array}$ & & & & & 2153 \\
\hline
\end{tabular}

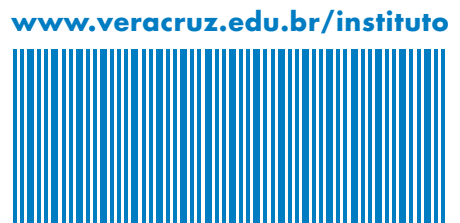

